\title{
Effect of obstructive sleep apnoea on retinal microvascular function: a randomised controlled trial
}

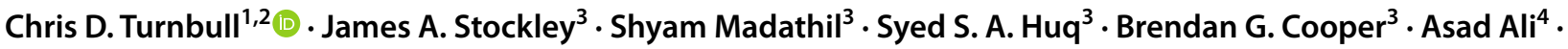 \\ Simon Wharton ${ }^{5} \cdot$ John R. Stradling ${ }^{2} \cdot$ Rebekka Heitmar $^{6}$
}

Received: 29 October 2021 / Revised: 28 January 2022 / Accepted: 15 February 2022 / Published online: 24 February 2022

(c) The Author(s) 2022

\begin{abstract}
Purpose Retinal microvascular endothelial dysfunction is thought to be of importance in the development of ocular vascular diseases. Obstructive sleep apnoea (OSA) causes macrovascular endothelial dysfunction, but the effect of OSA on retinal microvascular endothelial function is not known. We aimed to determine the effect of OSA on retinal microvascular function. Methods We conducted a multi-centre, double-blind, randomised, parallel, controlled trial in patients with known moderateto-severe OSA, established on continuous positive airway pressure (CPAP). Participants were randomised to 14 nights of either continued CPAP or sham CPAP to generate a return of OSA. Retinal vascular responses to flickering light were measured using dynamic vessel analysis both at baseline and after 14 nights of intervention. The primary outcome was the change from baseline to follow-up in the area under the curve of the arteriolar response to flickering light, sham CPAP versus continued CPAP.

Results Nineteen patients were randomised to sham CPAP, and 18 patients were randomised to continued CPAP. There was no significant effect of CPAP withdrawal and return of OSA on retinal responses, with a change in the area under the curve of the arteriole response to flickering light of +3.8 arbitrary units $(95 \% \mathrm{CI}-10.6$ to $+18.2, p=0.59)$, sham CPAP versus continued CPAP.

Conclusions CPAP withdrawal and a return of OSA had no significant effect on retinal microvascular responses. This contrasts with the effect of CPAP withdrawal on macrovascular endothelial function and suggests that OSA has different effects on macrovascular and microvascular endothelial function.

ISRCTN 78082983, 23/10/2014, Prospectively registered.

\section{Key messages}

- Obstructive sleep apnoea (OSA) is associated with ocular vascular diseases and macrovascular endothelial dysfunction but it is not known whether this is due to impaired retinal microvascular function.

- In our study, patients with established OSA were randomised to either stop treatment for two weeks, or continue their normal treatment. This led to a return of OSA, but did not impair retinal vascular function.

- In contrast to the effects on macrovascular endothelial dysfunction, stopping CPAP for two weeks had no effect on retinal microvascular function, which has implications in respect to the role of OSA in ocular vascular disease.
\end{abstract}

Keywords Obstructive sleep apnoea $\cdot$ Retinal vascular reactivity $\cdot$ Endothelial function $\cdot$ Autoregulation $\cdot$ Ocular vascular disease

Chris D. Turnbull

christopher.turnbull@ouh.nhs.uk

Extended author information available on the last page of the article 


\section{Introduction}

Obstructive sleep apnoea (OSA) causes impaired vascular function [1], and is associated with cardiovascular disease [2]. The retinal vasculature closely resembles the cerebral vasculature [3], and retinal vascular disease is associated with cerebrovascular disease [4].

The retinal vasculature plays a role in the pathogenesis of several eye diseases associated with OSA, including glaucoma, non-arteritic ischaemic optic neuropathy and diabetic retinopathy (DR) [5]. Endothelial dysfunction and impaired autoregulation are thought to underlie the development of DR [6]. Dynamic vessel analysis (DVA) allows assessment of retinal endothelial function using real-time recording of retinal vessel sizes in response to flickering light exposure [7]. DVA has demonstrated retinal endothelial dysfunction in patients with type 2 diabetes mellitus (T2DM) [8]. Whilst OSA has been shown to be a risk factor for more severe DR $[9,10]$, it is not known if this is due to OSA-induced retinal endothelial dysfunction.

Endothelial dysfunction is a precursor to atherosclerosis [11], along with retinal disease [6]. OSA causes endothelial dysfunction as measured using flow-mediated dilation (FMD) at the brachial artery [12, 13]. However, FMD is only weakly correlated with microvascular function, such as retinal vascular endothelial responses [14], which are important in the development of cardiovascular disease [15].

Retinal vasculature dysfunction may be important in the pathogenesis of eye diseases associated with OSA and provides a correlate of microvascular function important in cardiovascular disease. We aimed to investigate the effect of OSA on retinal vascular reactivity in patients without established eye disease or diabetes mellitus (DM).

\section{Methods}

The retinal reactivity in OSA study was a multi-centre, double-blind, randomised, parallel controlled trial. It was prospectively registered (ISRCTN 78082983) and ethically approved (NHS REC 14/SC/1235). All participants provided written informed consent.

\section{Participants and screening}

Participants were recruited from four hospital sleep clinics in the UK. Participants had an original diagnosis of moderateto-severe OSA, had no known history of DM and had been treated with continuous positive airway pressure (CPAP) for more than 6 months with mean CPAP usage exceeding $4 \mathrm{~h} /$ night in the 30 days prior to screening. Participants underwent screening involving home overnight pulse oximetry to ensure that their OSA was well controlled on CPAP and to ensure return of OSA on stopping CPAP. Further details along with full inclusion and exclusion criteria are listed in the online supplement (Suppl. P3-4).

\section{Randomisation, intervention and blinding}

Randomisations and interventions were performed as described in a previous CPAP withdrawal study [12]. Randomisation was carried out by an unblinded researcher not performing outcome assessments. Participants were randomised 1:1 using online randomisation software (http://www.sealedenvelope.com/) by minimised randomisation (minimised by the highest screening ODI off CPAP, $<$ or $\geq 33 / \mathrm{h}$; age, $<$ or $\geq 60$ years; BMI, $<$ or $\geq 34 \mathrm{~kg} /$ $\mathrm{m}^{2}$ ). Participants were randomised at baseline to receive either continued therapeutic CPAP or sham CPAP. Further details of the intervention are included on the online supplement (Suppl. P4-5). Participants and the researcher performing outcome assessments were blind to treatment allocations. All participants were instructed to use their allocated replacement CPAP machine overnight for 14 days and their own non-trial CPAP machine was retained at the study site for the intervention period.

\section{Procedures}

Full details of the study procedures and methodologies can be found in the online supplement (Suppl. P5-7).

\section{Retinal vessel reactivity to flicker light stimulation}

Dynamic vessel analysis (DVA, IMEDOS Systems, Jena, Germany) with a flickering light protocol [16] was performed during wakefulness at baseline and, at the same time of day, after 14 days of intervention. Full details of DVA analysis and flickering light protocol are provided in the online supplement. In brief, this enables continuous recordings of retinal vessel diameters before, during and after $20 \mathrm{~s}$ of flickering light, which is a powerful retinal metabolic stimulus which in health causes both retinal arteriolar and venular dilatation [16]. DVA assessment of retinal vessel diameters was also performed (before, during and after) whilst the patient's hand was submerged for $1 \mathrm{~min}$ into ice cold water $\left(0{ }^{\circ} \mathrm{C}\right)$ to elevate arterial blood pressure (see description of cold pressor test in the online supplement for full details).

\section{Ocular and systemic patient characteristics}

In addition to DVA, a detailed baseline and follow-up ophthalmic assessment was performed including visual fields 
assessment (HFA, Central 30-2 Threshold Test), intraocular pressure (rebound tonometry, I-CARE, Medline) and static retinal photography $\left(50^{\circ}\right.$ retinal photography, full colour and red free, Zeiss FF450+, Zeiss Meditech). Office blood pressure and heart rate were performed in triplicate after at least $5 \mathrm{~min}$ in a seated position. Participants were instructed to record home blood pressure and heart rate measurements in triplicate every morning in a seated position immediately after waking (Omron M10), from three mornings prior to their baseline visit until the end of follow-up. Participants were instructed to perform overnight pulse oximetry (300i; Konica Minolta) for each of the 14 intervention nights. Blood glucose measurements (random) were recorded at baseline and follow-up, and baseline glycosylated haemoglobin $(\mathrm{HbA} 1 \mathrm{c})$ levels were recorded. Baseline weight, height and neck circumference were recorded. Mean hours of pretrial CPAP usage were recorded over the 30 days prior to randomisation.

\section{Outcomes}

The primary outcome was the change from baseline to follow-up visit in retinal arteriolar diameter change to flicker light stimulation, defined as the area under the curve (AUC) during $20 \mathrm{~s}$ of the flickering light stimulation, averaged over three repeated flicker exposures, sham CPAP versus therapeutic CPAP (AUC (FL) see Fig. 1).

Secondary outcome measures included the AUC as defined as above for venular response to the flickering light protocol; the total arteriole AUC during and following the flickering light protocol; the total venular AUC during and following the flickering light protocol; and the area under the arterial curve following the end of the flicker light for a maximum of $20 \mathrm{~s}$ (AUC (Const) see Fig. 1). The maximal arteriolar dilation during the flickering light protocol, the maximal venular dilation during the flickering light protocol and the maximum arteriolar constriction following the flickering light all reported as the percentage change from baseline. The correlation of the primary outcome with the average overnight ODI during the last seven nights of CPAP withdrawal, the correlation of the primary outcome measure with the average overnight heart rate rises (rises $>6 \mathrm{bpm}$ from baseline) and the correlation of the primary outcome measure with the average home morning blood pressure on the last three mornings of CPAP withdrawal, were assessed. Retinal arteriole and venous responses during and after a cold pressor test were exploratory outcomes.

\section{Statistics}

Sample size estimation was based on data showing reduced retinal vascular reactivity of $1.4 \pm 1.8 \%$ in participants with T2DM but without known retinopathy, compared to $3.2 \pm 1.6 \%$ in controls [17]. In order not to miss a similar effect of OSA on the arteriole AUC during the flickering light protocol, with $90 \%$ power and with two-sided alpha of $0.05,20$ patients in each arm were required. Alternatively, brachial artery FMD is correlated to some extent with retinal reactivity [14], and CPAP withdrawal causes a 3.2\% reduction in FMD from a baseline of $5.2 \pm 2.6 \%$ [12]. In order not to miss a similar effect
Fig. 1 Schematic representation of the retinal vessel diameter and of the area under the curve measurements for primary and secondary outcome measures. AUC (FL), area under the curve for the $20 \mathrm{~s}$ during flickering light, which is the primary outcome. AUC (Const), area under the curve for the $20 \mathrm{~s}$ following flickering light

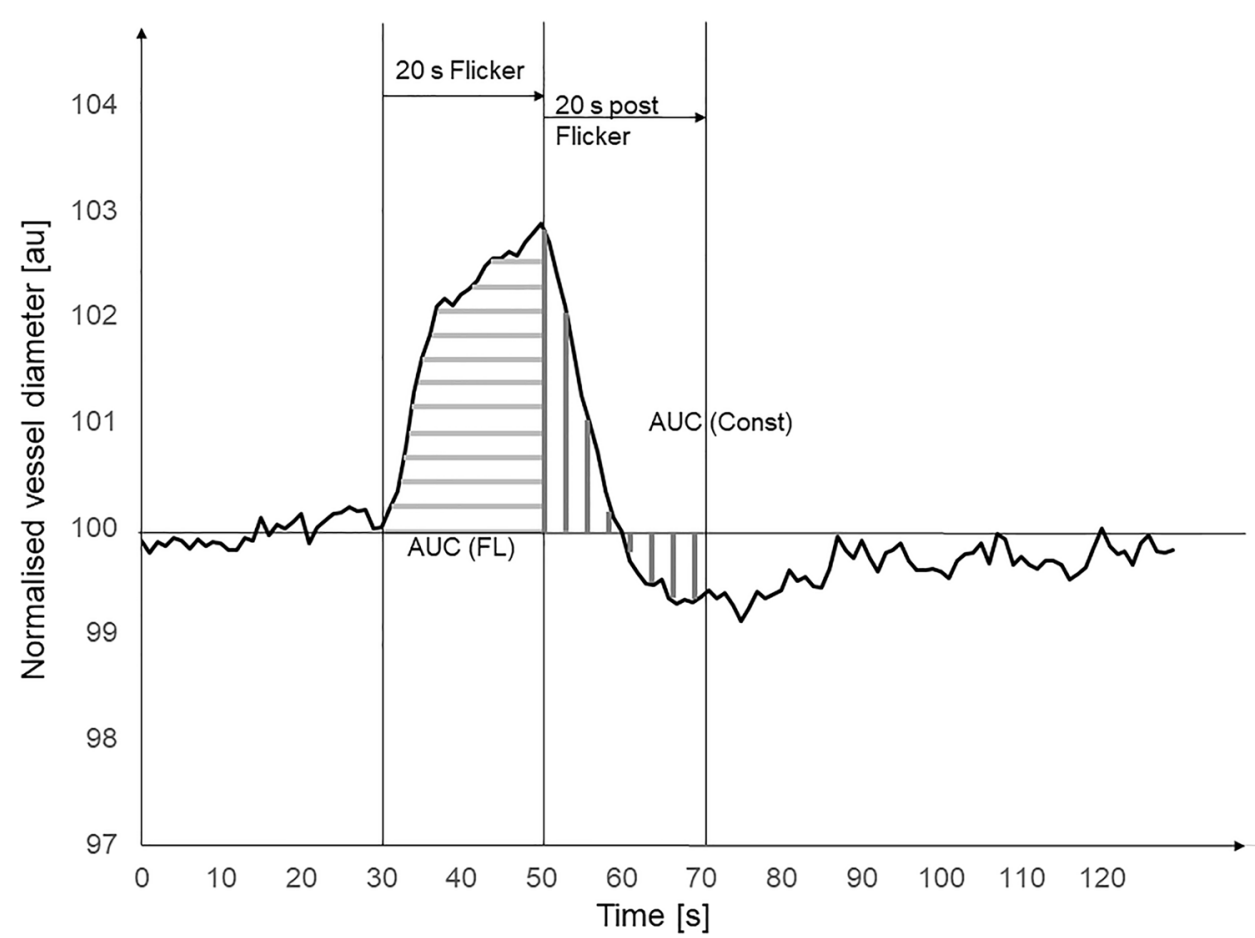


of OSA on the arteriole AUC during the flickering light protocol, with $90 \%$ power and with a two-sided alpha of 0.05 , 15 patients in each arm were required. We therefore aimed to recruit over 40 participants, so to account for any dropout.

Statistical analysis was carried out using SPSS Version 26.0 (IBM, USA). Continuous data were assessed for normality and expressed as mean \pm standard deviation where normally distributed and median (first quartile, third quartile) where non-normally distributed. Categorical data are expressed as number (percentage). Primary and secondary outcome analyses were performed using multi-variable linear regression adjusted with the dependent variable defined as the outcome variable at follow-up and the treatment effect modelled as the effect of sham CPAP versus therapeutic CPAP, with adjustments for baseline values, and further adjustments for OSA severity during screening, BMI, age and available relevant components of the Pocock cardiovascular risk score (smoking status, systolic blood pressure, prior cardiovascular disease) using an enter forward selection criteria $(p<0.10)$. A sensitivity analysis was performed excluding participants with $\mathrm{HbAlc}$ values indicative of new diagnoses of T2DM (HbA1c $>6.4 \mathrm{mmol} / \mathrm{mol})$. Univariate correlations were assessed using Pearson's or Spearman rank correlation as appropriate.

\section{Results}

Thirty-seven participants were recruited from January 2015 until March 2020, when a decision was taken to close the study due to study-site closures resulting from the coronavirus pandemic. Details of the participants and randomisation are included in the study flow diagram (Fig. 2). Baseline characteristics were similar for both groups, with similar pre-trial OSA severity, OSA control and CPAP adherence (see Table 1).

\section{Baseline ocular assessments}

Baseline intraocular pressure and visual field measurements were conducted to exclude significant baseline eye disease. Intraocular pressure and visual fields were comparable at baseline between both groups and within the normal ranges (Table 2).

\section{Primary and secondary outcome measures}

One patient in the sham CPAP group and two patients in the CPAP group had technically insufficient traces that did not allow measurement of arterial responses to flickering light, giving a total of 34 patients in whom primary outcome assessment was possible.

At baseline, there was a chance difference in the AUC for the mean arteriolar response to the flickering light protocol for sham CPAP $(28.2 \pm 26.2$ arbitrary units or AU) compared to therapeutic CPAP $(50.7 \pm 30.3 \mathrm{AU})$.

There was no significant change in the primary outcome with no effect of sham CPAP on the change in the AUC for arteriolar response to flickering light of $+3.8 \mathrm{AU}$ (95\% CI -10.6 to $+18.2, p=0.59$, Fig. 3 ) versus continued CPAP.
Fig. 2 Study flow diagram showing potential participants who underwent screening oximetry. CPAP, continuous positive airway pressure

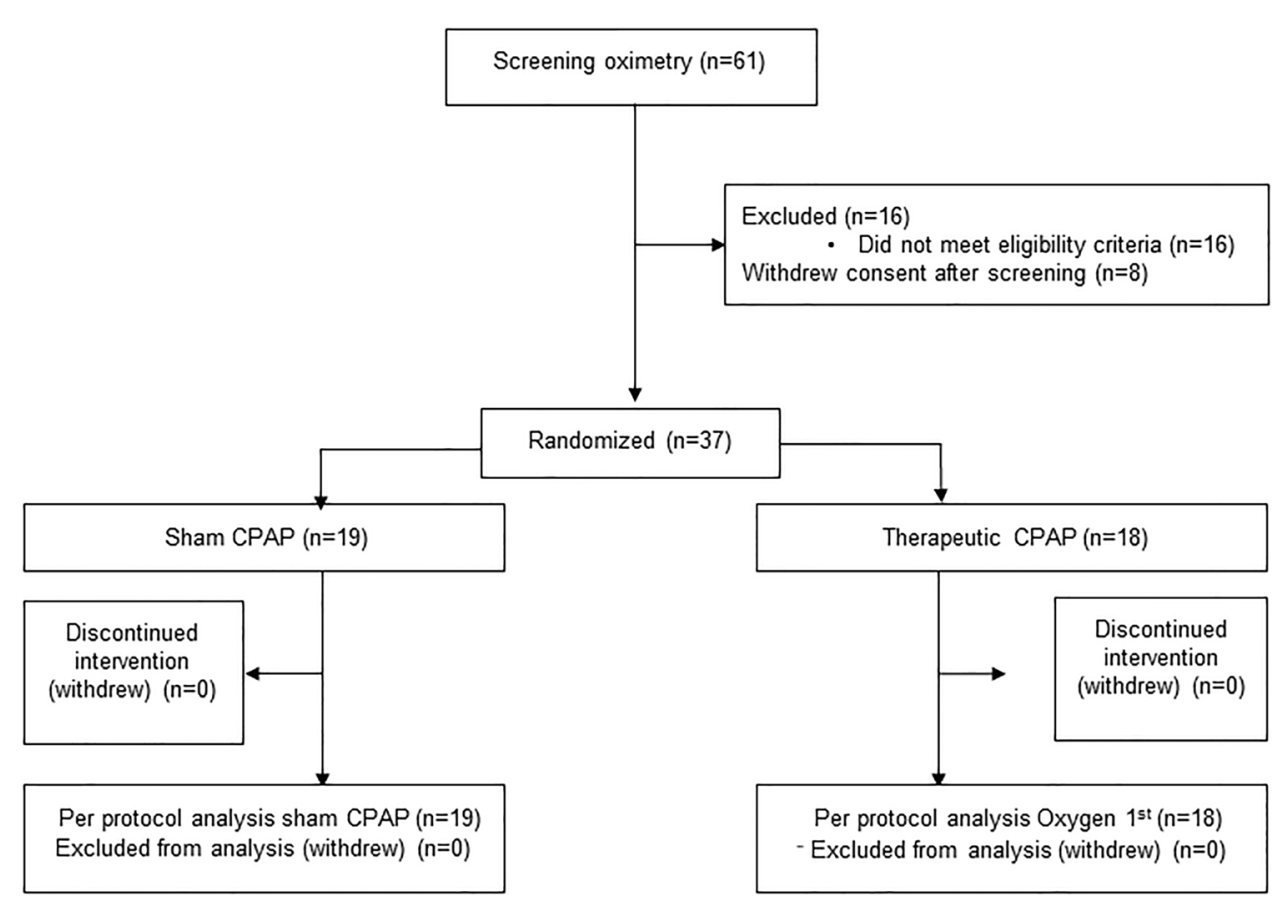


Table 1 Baseline characteristics. Continuous data displayed as either mean \pm standard deviation if normally distributed or median (first quartile, third quartile) if non-normally distributed. Categorical data displayed as number (percentage). $B M I$, body mass index; $C P A P$, continuous positive airway pressure; $I H D$, ischaemic heart disease; $H b A l c$, glycosylated haemoglobin; $O D I$, oxygen desaturation $\geq 4 \%$ index

\begin{tabular}{|c|c|c|}
\hline & $\mathrm{CPAP}(n=18)$ & Sham CPAP $(n=19)$ \\
\hline Age (years) & $61.3 \pm 8.5$ & $60.0 \pm 8.8$ \\
\hline \multicolumn{3}{|l|}{ Ethnicity } \\
\hline - White & $17(94 \%)$ & $18(95 \%)$ \\
\hline - Asian & $1(6 \%)$ & $0(0 \%)$ \\
\hline - Hispanic & $0(0 \%)$ & $1(5 \%)$ \\
\hline \multicolumn{3}{|l|}{ Gender } \\
\hline - Male & $14(78 \%)$ & $15(79 \%)$ \\
\hline - Female & $4(22 \%)$ & $4(21 \%)$ \\
\hline \multicolumn{3}{|l|}{ Smoking status } \\
\hline - Never smoker & $9(50 \%)$ & $9(47 \%)$ \\
\hline - Ex-smoker & $9(50 \%)$ & $8(42 \%)$ \\
\hline - Current smoker & $0(0 \%)$ & $2(11 \%)$ \\
\hline Smoking (pack years) & $18.0(9.3,28.5)$ & $17.0(8.8,27.5)$ \\
\hline Hypertension & $11(61 \%)$ & $9(47 \%)$ \\
\hline Hypercholesterolemia & $2(11 \%)$ & $1(5 \%)$ \\
\hline IHD or stroke & $2(11 \%)$ & $0(0 \%)$ \\
\hline Atrial fibrillation & $1(6 \%)$ & $0(0 \%)$ \\
\hline Neck circumference $(\mathrm{cm})$ & $43.1 \pm 4.9$ & $43.4 \pm 3.6$ \\
\hline BMI $\left(\mathrm{kg} / \mathrm{m}^{2}\right)$ & $35.8 \pm 4.9$ & $36.6 \pm 5.2$ \\
\hline $\mathrm{HbA1C}(\%)$ & $5.5(5.3,5.8)$ & $5.7(5.2,5.9)$ \\
\hline Random glucose measurement (mg/dL) & $102.6(84.6,119.7)$ & $111.6(93.6,131.4)$ \\
\hline CPAP compliance $(\mathrm{h} / \mathrm{n})$ & $6.4 \pm 1.1$ & $6.1 \pm 1.4$ \\
\hline Screening ODI off CPAP $(/ \mathrm{h})$ & $32.7(22.9,47.7)$ & $37.5(27.8,70.3)$ \\
\hline Screening ODI on CPAP $(/ \mathrm{h})$ & $5.1 \pm 2.4$ & $5.1 \pm 2.3$ \\
\hline Baseline ESS & $5.4 \pm 4.5$ & $5.7 \pm 4.2$ \\
\hline
\end{tabular}

Table 2 Baseline intraocular pressure and visual field assessments. Data expressed as either mean \pm standard deviation if normally distributed or median (first quartile, third quartile) if not normally distributed, and categorical data displayed as number (percentage). $M D$, mean deviation; $P S D$, pattern standard deviation

\begin{tabular}{lll}
\hline & CPAP & Sham CPAP \\
\hline $\begin{array}{lll}\text { Intraocular pressure } \\
\quad \text { Right intraocular pressure }(\mathrm{mmHg})\end{array}$ & $16.7 \pm 2.8$ & $15.8 \pm 3.7$ \\
$\quad$ Left intraocular pressure $(\mathrm{mmHg})$ & $16.2 \pm 3.0$ & $15.5 \pm 4.3$ \\
Visual field & & \\
$\quad$ Foveal threshold (dB) & $32.8 \pm 2.5$ & $33.3 \pm 3.3$ \\
30-2 MD (dB) & $-1.6 \pm 1.8$ & $-1.7 \pm 1.4$ \\
30-2 PSD (dB) & $2.0(1.6,2.3)$ & $2.0(1.7,2.5)$ \\
\hline
\end{tabular}

There were no significant differences in the treatment effect of sham CPAP in other secondary outcome measures (see Table 3).

\section{CPAP withdrawal}

Full results of the effect of CPAP withdrawal on overnight pulse oximetry, Epworth sleepiness score (ESS), home morning blood pressure and heart rate measurements and

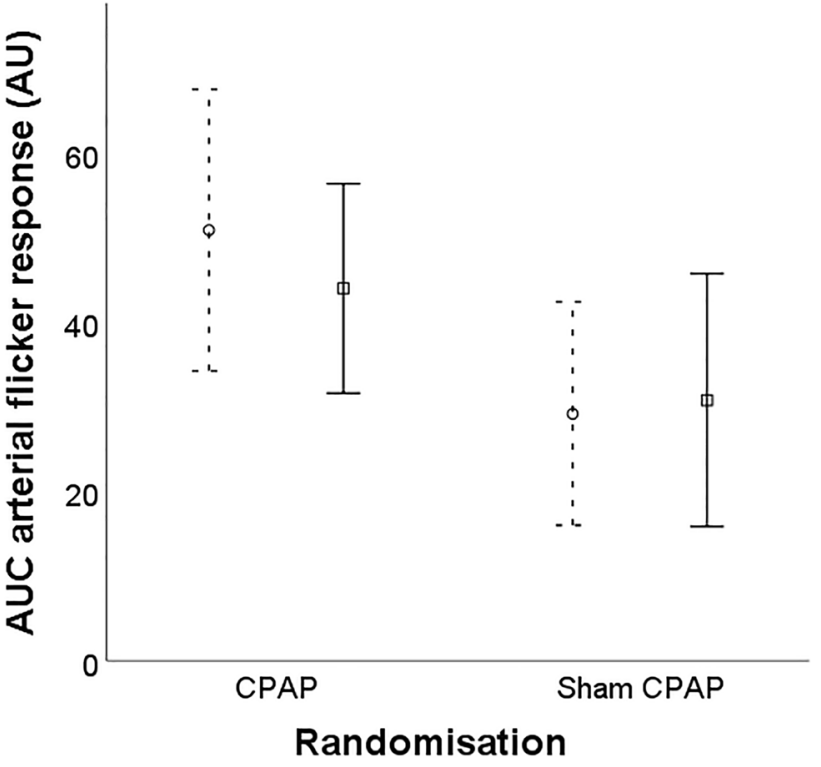

Fig. 3 Plot showing the area under the curve value increase in arteriole diameter during flickering exposure, proportional to baseline diameter, for CPAP and sham CPAP. Circles and squares represent baseline and follow-up mean values respectively with dotted and solid lines representing baseline and follow-up 95\% confidence intervals, respectively. AUC, area under the curve; CPAP, continuous positive airway pressure 
Table 3 Primary and secondary outcome data showing baseline and follow-up values for optic assessments along with the modelled treatment effect and 95\% CI. Data displayed as either mean \pm standard deviation if normally distributed or median (first quartile, third quartile) if non-normally distributed. Treatment effect of CPAP withdrawal modelled using multi-variable linear regression with follow-up value as the dependent variable, treatment (CPAP or sham) as a fixed effect, with adjustment for baseline value and further adjustments for age, gender, stroke, IHD, HbA1c, smoking status, systolic blood pressure, BMI and OSA severity during screening using an enter forward selection criteria $(p<0.10)$. AUC, area under the curve; $A V R$, central retinal artery to central retinal vein ratio; $C P A P$, continuous positive airway pressure; $C R A E$, central retinal artery equivalent; $C R V E$, central retinal vein equivalent

\begin{tabular}{|c|c|c|c|c|c|c|c|}
\hline & \multicolumn{2}{|l|}{ CPAP } & \multicolumn{2}{|l|}{ Sham CPAP } & \multirow[t]{2}{*}{ Treatment effect } & \multirow[t]{2}{*}{$95 \% \mathrm{CI}$} & \multirow[t]{2}{*}{$p$ value } \\
\hline & Baseline & Follow-up & Baseline & Follow-up & & & \\
\hline \multicolumn{8}{|c|}{ Primary outcome: dynamic retinal arteriole response to flickering light protocol } \\
\hline $\begin{array}{l}\text { AUC Flicker } \\
\text { arterial }\end{array}$ & $50.7 \pm 30.3$ & $44.0 \pm 23.2$ & $28.2 \pm 26.2$ & $30.8 \pm 30.1$ & +3.8 & -10.6 to +18.2 & 0.59 \\
\hline \multicolumn{8}{|c|}{ Secondary outcomes: dynamic retinal arteriole response to flickering light protocol } \\
\hline $\begin{array}{l}\text { Maximal dila- } \\
\text { tion }(\%)\end{array}$ & $4.4 \pm 1.7$ & $4.3 \pm 1.3$ & $3.0 \pm 1.5$ & $3.2 \pm 2.2$ & -0.1 & -1.3 to +1.1 & 0.87 \\
\hline $\begin{array}{l}\text { AUC Flicker } \\
\text { constriction }\end{array}$ & $\begin{array}{l}-4.8 \\
(-13.7,+3.8)\end{array}$ & $\begin{array}{l}-1.2 \\
(-18.1,+10.3)\end{array}$ & $\begin{array}{l}-15.8 \\
(-34.4,-5.5)\end{array}$ & $\begin{array}{l}-11.3 \\
(-35.4,-5.8)\end{array}$ & -5.9 & -16.4 to +4.5 & 0.25 \\
\hline $\begin{array}{l}\text { Maximal } \\
\text { constriction } \\
(\%)\end{array}$ & $\begin{array}{l}-1.0 \\
\quad(-1.7,-0.7)\end{array}$ & $\begin{array}{l}-1.0 \\
\quad(-2.2,-0.0)\end{array}$ & $\begin{array}{l}-1.7 \\
\quad(-3.0,-1.2)\end{array}$ & $\begin{array}{l}-2.3 \\
(-3.3,-1.1)\end{array}$ & -0.6 & -1.1 to +0.0 & 0.05 \\
\hline $\begin{array}{l}\text { Baseline } \\
\text { diameter } \\
\text { fluctuation }\end{array}$ & $2.5 \pm 1.4$ & $2.4 \pm 1.1$ & $2.0 \pm 1.1$ & $2.3 \pm 1.1$ & +0.0 & -0.6 to +0.7 & 0.95 \\
\hline $\begin{array}{l}\text { Dilation } \\
\text { amplitude }\end{array}$ & $5.2(4.3,7.4)$ & $5.0(3.5,7.3)$ & $4.4(3.8,6.3)$ & $5.0(3.5,6.7)$ & +0.6 & -0.8 to +2.0 & 0.38 \\
\hline Arteriole size & $109.0 \pm 18.3$ & $109.5 \pm 15.7$ & $107.6 \pm 13.5$ & $108.2 \pm 13.9$ & -1.3 & -5.4 to +2.8 & 0.53 \\
\hline \multicolumn{8}{|c|}{ Secondary outcomes: dynamic retinal venule response to flickering light protocol } \\
\hline AUC Flicker & $51.7 \pm 23.1$ & $49.3 \pm 25.2$ & $43.2 \pm 18.9$ & $36.8 \pm 18.1$ & -6.0 & -20.1 to +8.0 & 0.39 \\
\hline $\begin{array}{l}\text { Max dilation } \\
(\%)\end{array}$ & $4.7 \pm 1.6$ & $4.9 \pm 2.0$ & $4.4 \pm 1.9$ & $4.1 \pm 1.5$ & -0.7 & -1.9 to +0.6 & 0.28 \\
\hline $\begin{array}{l}\text { Baseline } \\
\text { diameter } \\
\text { fluctuation }\end{array}$ & $1.4(1.0,2.2)$ & $1.8(1.3,2.2)$ & $1.5(1.2,2.4)$ & $1.8(1.3,3.6)$ & -0.1 & -0.9 to +0.6 & 0.71 \\
\hline Venule size & $139.7 \pm 23.8$ & $143.1 \pm 24.3$ & $146.7 \pm 19.0$ & $147.4 \pm 20.1$ & -1.3 & -4.3 to 1.6 & 0.37 \\
\hline \multicolumn{8}{|c|}{ Static retinal photography } \\
\hline CRAE & $\begin{array}{l}150.0(145.5, \\
163.5)\end{array}$ & $\begin{array}{c}152.5(142.3 \\
169.0)\end{array}$ & $\begin{array}{l}160.0(154.0, \\
166.0)\end{array}$ & $\begin{array}{l}156.0(151.0 \\
169.0)\end{array}$ & -2.3 & -7.0 to +2.4 & 0.33 \\
\hline CRVE & $203.7 \pm 20.7$ & $206.0 \pm 23.1$ & $211.1 \pm 17.0$ & $211.2 \pm 18.1$ & +0.8 & -3.3 to +5.0 & 0.68 \\
\hline AVR & $0.75(0.72,0.78)$ & $0.77(0.72,0.79)$ & $0.76(0.72,0.79)$ & $0.75(0.71,0.78)$ & -0.01 & $-0.03,+0.01$ & 0.22 \\
\hline
\end{tabular}

office blood pressure and heart rate measurements are shown in Table $\mathrm{S} 1$ in the online supplement.

CPAP withdrawal led to a marked return of OSA and an increase in daytime sleepiness, with an increase in the ODI of $27.5 / \mathrm{h}(95 \%$ CI 16.7 to $38.3, p<0.001)$ and an increase in the ESS of 3.5 points (95\% CI 1.7 to $5.4, p=0.001$ ).

CPAP withdrawal significantly increased home morning heart rate and office heart rate $(p=0.01$ and 0.02 , respectively), but the rises in home or office systolic or diastolic blood pressure did not reach statistical significance (see Table S1 in the online supplement).

There were no significant correlations between the change in the AUC of the arteriole response to the flicker light protocol and the trial ODI, the heart rate rises $(>6 \mathrm{pm})$ index (a marker of 'autonomic' arousals during sleep), the change in home morning systolic blood pressure or the change in home morning diastolic blood pressure in the sham CPAP arm (Table S2 in the online supplement).

\section{Cold pressor test}

As expected, the cold pressor test statistically significantly increased systolic and diastolic blood pressure (Table S3 in the online supplement). Retinal arteriole and venous vessel diameters were comparable at baseline during 1 min of recording prior to cold pressor test at both the baseline and follow-up visits (Table S4 in the online supplement). CPAP withdrawal caused an unexpected small but significant 
increase in the maximal retinal arteriole vasoconstriction during the cold pressor test (treatment effect $1.3 \%, 95 \%$ CI 0.2 to $2.3 \%, p=0.02$ ). There were no other significant effects of CPAP withdrawal on cold pressor arteriole or venous responses (Table $\mathrm{S} 4$ in the online supplement).

\section{Baseline glycaemic assessment}

HbA1C measurements were taken at baseline to identify those at risk of undiagnosed diabetes. HbA1C measurements were available for 36 of the 37 participants. In one participant randomised to sham CPAP, the HbA1c sample was inadequate. Two participants (one randomised to sham CPAP with a value of $7.4 \%$ and one randomised to therapeutic CPAP with a value of $6.6 \%$ ) had $\mathrm{HbA1c}$ values above $6.4 \%$, consistent with undiagnosed T2DM.

A sensitivity analysis excluding the two participants with HbAlc values $>6.4 \%$ was conducted for the primary outcome measure. This showed similar results, with no significant change in AUC for the arteriolar response to flickering light with a treatment effect of sham CPAP of $5.5 \mathrm{AU}(95 \%$ CI -10.0 to $+21.0, p=0.47)$.

\section{Discussion}

Fourteen days of CPAP withdrawal had no significant effect on retinal microvascular function measured with the flickering light protocol. CPAP withdrawal caused a clear return of intermittent hypoxia, daytime sleepiness and a rise in morning heart rate consistent with returning moderate-to-severe OSA, both in terms of symptoms and physiological effect. Despite these effects of CPAP withdrawal, it had no significant effect on the primary outcome or any other measure of retinal microvascular response to flickering light; furthermore, it did not reduce retinal arteriolar vasoconstriction in response to the cold pressor test, and in fact increased it. To our knowledge, this is the first randomised controlled trial to report on the effects of stopping CPAP treatment for 14 days, in patients with OSA on both static and dynamic retinal vessel parameters.

\section{Ocular endothelial function}

Retinal vessel responses to flickering light are a measure of microvascular nitric oxide-mediated endothelial function [18]. A small number of case-cohort studies exploring choroidal and central retinal blood flow using laser colour Doppler or applanation tonometry in OSA have been summarised previously [19], but these do not directly assess retinal microvascular responses. Optical coherence tomography angiography (OCTA) has also been used to assess the retinal microvasculature in a small number of non-randomised studies, but these are limited by matching [20, 21], or by characterising patients only by OSA risk rather than sleep studies [22]. Retrobulbar blood flow velocities have been reported to be increased in moderate-to-severe OSA in comparison with unmatched controls of similar age [23].

Fourteen days of exposure to intermittent hypoxia in rats showed oxidative stress in the ophthalmic artery associated with endothelial dysfunction mediated through nitric oxide and endothelium-derived hyperpolarising factor pathways [24]. However, the role of oxidative stress in OSA-mediated ocular vascular disease is contentious [25, 26], and such animal models often induce more marked intermittent hypoxia than seen in human OSA, and do not model for the correct associated rises in carbon dioxide levels that would generate vasodilation [27]. In addition, there are substantial differences in the blood supply distribution to the retina in rats compared with humans [28].

None of these experiments adequately examine the effects of human OSA on the retinal microvasculature. OSA has been reported to decrease the static arterio-venous ratio and attenuating retinal vascular pulsation [29]. Furthermore, patients with severe OSA who were not treated with CPAP had progressive reductions in static arterio-venous ratio, compared with those on CPAP, but CPAP had no effect on retinal vessel pulsatility [30]. There are key differences between these studies and ours. First, the measured arteriovenous ratio is not a dynamic measurement of retinal vascular function, unlike our dynamic retinal vessel analyses. Retinal pulsatility may be a measure of retinal vascular function but approaches to measure pulsatility are not standardised and are dependent on vessel diameter, location and axial length. Finally, these previous reports were not randomised as our study was. Comparing the effect of CPAP in nonrandomised patients who are either on or not on CPAP is prone to bias and other factors. Nevertheless, these studies highlight the possibility that OSA may have deleterious effects on the retinal vasculature which were not apparent after 14 days of CPAP withdrawal.

\section{Comparisons with systemic endothelial function}

OSA impairs endothelial function as measured by FMD in the brachial artery [31,32]. For example, in contrast to our findings, an almost identical experimental paradigm found a $61 \%$ reduction in FMD after 14 days of CPAP withdrawal [12].

CPAP withdrawal, as a model of returning OSA, appears to have contrasting effects on endothelial function. There are marked reductions in macrovascular endothelial function as measured by brachial artery FMD [12], but no effect on several measures of microvascular function including cerebral vascular reactivity [33], myocardial perfusion and renal and dermal microvascular function [34], and no significant 
effect on retinal microvascular function in our study. These contrasting findings support the concept of differing effects of OSA on endothelial function in microvascular and macrovascular vessels.

Differing contributions of nitric oxide in macrovascular and microvascular endothelial function could explain these differences. Nitric oxide blockade abolishes macrovascular endothelial responses [35, 36], whilst only partially attenuating retinal [18], and other microvascular endothelial responses [37]. In addition, glial cells-which are not present outside of the nervous system - play an important role in retinal hyperaemia [38], which may contribute to differing responses between retinal arterioles and the brachial artery.

\section{Retinal pressure autoregulation}

Retinal blood flow autoregulation has both metabolic-as assessed by the flickering light protocol—and blood pressure components. Pressure autoregulation refers to the maintenance of a constant blood flow despite varied ocular perfusion pressures. Retinal vessel vasoconstriction in response to increased central blood pressure is impaired in retinal vascular disease [39]. However, our study showed that CPAP withdrawal did not impair cold pressor-induced vasoconstriction. Retinal vasoconstriction in response to raised central blood pressure diminishes with age [40], and it is possible that the older age of our participants accounts for the small vasoconstriction responses we observed in response to cold pressor testing. Intriguingly, we observed a paradoxical increase in vasoconstriction with CPAP withdrawal. This was an exploratory outcome and requires validation. This suggests that OSA does not impair retinal pressure autoregulation, at least in the short term and in the absence of eye disease.

\section{Diabetic retinopathy (DR) and OSA}

OSA is associated with increased risk of more advanced DR [9], and may be associated with an increased risk of DR $[9,41]$. The exact mechanisms for accelerated retinopathy are not clear but might include endothelial dysfunction [5]. Both DR [42, 43] and probably DM alone [17] are associated with decreased retinal vascular reactivity, as a marker of endothelial function. A key aim of this study was to understand if OSA impairs retinal vascular reactivity in patients free from T2DM. Our data shows that short-term return of OSA during 14 days of CPAP withdrawal does not alter static retinal vessel calibres or retinal vessel reactivity to flicker light. However, there may be different effects on these parameters in those with underlying diabetes mellitus, or those exposed to OSA in the longer term. The only randomised trial to examine the longer term effects of
CPAP treatment for OSA on progression of DR showed no benefit; however, it was limited by CPAP usage of $3.2 \mathrm{~h} / \mathrm{night}$ [44], meaning that further work with long-term follow-up and optimised CPAP adherence is needed.

\section{Strengths and limitations of our study}

This study has strengths and limitations. The use of a robust randomised design, the inclusion of patients with excellent CPAP compliance and the detailed and standardised measurements of pulse oximetry tracings and ophthalmic parameters are strengths of this study [45]. Our study was limited by a small sample size and early closure, three patients short of its recruitment target. However, our target allowed from dropouts, of which there were none and it was powered to show an OSA-related reduction in retinal reactivity of similar magnitude to the effect of DM [17], and to show a similar magnitude of reduction in endothelial function as previously reported in the brachial artery during CPAP withdrawal [12]. There are no prior data solely exploring the effects of OSA on retinal vascular reactivity and the minimal clinically important change in retinal vascular response to the flickering light protocol is not known. The 95\% CI for change in arteriolar AUC in response to flickering light in the sham CPAP arm was -10.6 to +18.2 , which represents up to a possible $37.6 \%$ deterioration relative to the baseline value. Therefore, we are confident that we have excluded a reduction in retinal vascular reactivity during CPAP withdrawal of a similar magnitude to the $61.4 \%$ decline in endothelial function measured in a similar experimental paradigm using flow-mediated dilation at the brachial artery [12]. This supports the view that the effect of OSA on endothelial function varies by vascular bed. In our study, CPAP was only withdrawn for 14 days, which is a short duration compared to the long-term effects of T2DM on retinal vasculature. It may be that 14 days of CPAP withdrawal do not replicate the longer term effects of untreated OSA; however, there are ethical concerns about withdrawing CPAP for longer periods of time. In the future, in order to gain further insights into the effects of OSA on the retinal vasculature, it may be necessary to utilise new approaches and techniques. Propensity matching has been suggested as an alternate method to traditional RCTs [46], but this is controversial [47]. Techniques such as ocular coherence tomography angiography have the potential to assist with determining the effects of OSA on the retinal vasculature and are becoming more readily available. 


\section{Conclusions}

Fourteen nights of CPAP withdrawal had no significant effect on retinal microvascular endothelial function in response to a flickering light protocol. CPAP withdrawal did cause a marked increase in intermittent hypoxia, daytime sleepiness and heart rate, consistent with the return of OSA and its consequences. These results contrast with the finding that CPAP withdrawal causes endothelial dysfunction at the brachial artery. This suggests that OSA may have different effects on endothelial function in the microvasculature, as compared to larger conduit vessels, and further work is needed to confirm this.

Supplementary Information The online version contains supplementary material available at https://doi.org/10.1007/s00417-022-05596-8.

Acknowledgements The authors would like to thank the patients who participated in this work. In addition, the authors would like to thank staff in Oxford Respiratory Trials Unit, University Hospitals Birmingham NHSFT (Queen Elizabeth Hospital \& Heartlands Hospital) and University Hospitals Coventry and Warwickshire who helped with the running and recruitment of this trial.

Author contribution CDT, RH and JRS designed and developed the protocol. CDT and RH carried out the data analysis. CDT drafted the manuscript. All authors read and approved the final version of the manuscript.

Funding This study was funded by the Oxford Radcliffe Hospitals Charitable Fund 0189 and the ResMed Foundation. Neither funder had any role in the design, conduct or analysis of this study.

\section{Declarations}

Ethics approval All procedures performed in the studies involving human participants were in accordance with the ethical standards of the NHS Research Ethics standard (NHS REC 14/SC/1235) and with the 1964 Helsinki declaration and its later amendments.

Informed written consent Written informed consent was obtained from all individual participants included in the study.

Conflict of interest Author Prof Stradling reports personal consulting fees from Bayer and Resmed UK, outside the scope of this work. Author Dr Turnbull reports personal consulting fees from Bayer, outside the scope of this work. There are no other relevant disclosures.

Open Access This article is licensed under a Creative Commons Attribution 4.0 International License, which permits use, sharing, adaptation, distribution and reproduction in any medium or format, as long as you give appropriate credit to the original author(s) and the source, provide a link to the Creative Commons licence, and indicate if changes were made. The images or other third party material in this article are included in the article's Creative Commons licence, unless indicated otherwise in a credit line to the material. If material is not included in the article's Creative Commons licence and your intended use is not permitted by statutory regulation or exceeds the permitted use, you will need to obtain permission directly from the copyright holder. To view a copy of this licence, visit http://creativecommons.org/licenses/by/4.0/.

\section{References}

1. Kohler M, Stradling JR (2010) Mechanisms of vascular damage in obstructive sleep apnea. Nat Rev Cardiol 7:677-685. https:// doi.org/10.1038/nrcardio.2010.145

2. Marin JM, Carrizo SJ, Vicente E, Agusti AG (2005) Long-term cardiovascular outcomes in men with obstructive sleep apnoeahypopnoea with or without treatment with continuous positive airway pressure: an observational study. Lancet 365:1046-1053. https://doi.org/10.1016/S0140-6736(05)71141-7

3. Cabrera DeBuc D, Somfai GM, Koller A (2017) Retinal microvascular network alterations: potential biomarkers of cerebrovascular and neural diseases. Am J Physiol Heart Circ Physiol 312:H201-H212. https://doi.org/10.1152/ajpheart.00201.2016

4. Baker ML, Hand PJ, Wang JJ, Wong TY (2008) Retinal signs and stroke: revisiting the link between the eye and brain. Stroke 39:1371-1379. https://doi.org/10.1161/STROKEAHA.107. 496091

5. West SD, Turnbull C (2018) Obstructive sleep apnoea. Eye (Lond) 32:889-903. https://doi.org/10.1038/s41433-017-0006-y

6. Bek T (2017) Diameter changes of retinal vessels in diabetic retinopathy. Curr Diab Rep 17:82. https://doi.org/10.1007/ s11892-017-0909-9

7. Heitmar R, Blann AD, Cubbidge RP, Lip GY, Gherghel D (2010) Continuous retinal vessel diameter measurements: the future in retinal vessel assessment? Invest Ophthalmol Vis Sci 51:5833-5839. https://doi.org/10.1167/iovs.09-5136

8. Sorensen BM, Houben AJ, Berendschot TT, Schouten JS, Kroon AA, van der Kallen CJ, Henry RM, Koster A, Sep SJ, Dagnelie PC, Schaper NC, Schram MT, Stehouwer CD (2016) Prediabetes and type 2 diabetes are associated with generalized microvascular dysfunction: the Maastricht study. Circulation 134:1339-1352. https://doi.org/10.1161/CIRCULATIONAHA. 116.023446

9. Leong WB, Jadhakhan F, Taheri S, Chen YF, Adab P, Thomas GN (2016) Effect of obstructive sleep apnoea on diabetic retinopathy and maculopathy: a systematic review and meta-analysis. Diabet Med 33:158-168. https://doi.org/10.1111/dme.12817

10. West SD, Groves DC, Lipinski HJ, Nicoll DJ, Mason RH, Scanlon PH, Stradling JR (2010) The prevalence of retinopathy in men with type 2 diabetes and obstructive sleep apnoea. Diabet Med 27:423-430. https://doi.org/10.1111/j.1464-5491.2010.02962.x

11. Gimbrone MA Jr, Garcia-Cardena G (2016) Endothelial cell dysfunction and the pathobiology of atherosclerosis. Circ Res 118:620-636. https://doi.org/10.1161/CIRCRESAHA.115.306301

12. Kohler M, Stoewhas AC, Ayers L, Senn O, Bloch KE, Russi EW, Stradling JR (2011) Effects of continuous positive airway pressure therapy withdrawal in patients with obstructive sleep apnea: a randomized controlled trial. Am J Respir Crit Care Med 184:1192-1199. https://doi.org/10.1164/rccm.201106-0964OC

13. Schwarz EI, Puhan MA, Schlatzer C, Stradling JR, Kohler M (2015) Effect of CPAP therapy on endothelial function in obstructive sleep apnoea: a systematic review and meta-analysis. Respirology 20:889-895. https://doi.org/10.1111/resp.12573

14. Pemp B, Weigert G, Karl K, Petzl U, Wolzt M, Schmetterer L, Garhofer G (2009) Correlation of flicker-induced and flow-mediated vasodilatation in patients with endothelial dysfunction and healthy volunteers. Diabetes Care 32:1536-1541. https://doi.org/ $10.2337 / \mathrm{dc} 08-2130$

15. Severino P, D’Amato A, Pucci M, Infusino F, Adamo F, Birtolo LI, Netti L, Montefusco G, Chimenti C, Lavalle C, Maestrini V, Mancone M, Chilian WM, Fedele F (2020) Ischemic heart disease pathophysiology paradigms overview: from plaque activation to microvascular dysfunction. Int J Mol Sci 21. https://doi.org/10. 3390/ijms 21218118 
16. Garhofer G, Bek T, Boehm AG, Gherghel D, Grunwald J, Jeppesen P, Kergoat H, Kotliar K, Lanzl I, Lovasik JV, Nagel E, Vilser W, Orgul S, Schmetterer L, Ocular Blood Flow Research A (2010) Use of the retinal vessel analyzer in ocular blood flow research. Acta Ophthalmol 88:717-722. https://doi.org/10.1111/j. 1755-3768.2009.01587.x

17. Chittari MV, McTernan P, Bawazeer N, Constantinides K, Ciotola M, O'Hare JP, Kumar S, Ceriello A (2011) Impact of acute hyperglycaemia on endothelial function and retinal vascular reactivity in patients with type 2 diabetes. Diabet Med 28:450-454. https:// doi.org/10.1111/j.1464-5491.2010.03223.x

18. Dorner GT, Garhofer G, Kiss B, Polska E, Polak K, Riva CE, Schmetterer L (2003) Nitric oxide regulates retinal vascular tone in humans. Am J Physiol Heart Circ Physiol 285:H631-636. https://doi.org/10.1152/ajpheart.00111.2003

19. Mentek M, Aptel F, Godin-Ribuot D, Tamisier R, Pepin JL, Chiquet C (2018) Diseases of the retina and the optic nerve associated with obstructive sleep apnea. Sleep Med Rev 38:113-130. https:// doi.org/10.1016/j.smrv.2017.05.003

20. Cai Y, Sun GS, Zhao L, Han F, Zhao MW, Shi X (2020) Quantitative evaluation of retinal microvascular circulation in patients with obstructive sleep apnea-hypopnea using optical coherence tomography angiography. Int Ophthalmol 40:3309-3321. https:// doi.org/10.1007/s10792-020-01518-x

21. Yu J, Xiao K, Huang J, Sun X, Jiang C (2017) Reduced retinal vessel density in obstructive sleep apnea syndrome patients: an optical coherence tomography angiography study. Invest Ophthalmol Vis Sci 58:3506-3512. https://doi.org/10.1167/iovs.17-21414

22. Venkatesh R, Pereira A, Aseem A, Jain K, Sangai S, Shetty R, Yadav NK (2021) Association Between Sleep Apnea Risk Score and Retinal Microvasculature Using Optical Coherence Tomography Angiography. Am J Ophthalmol 221:55-64. https://doi.org/ 10.1016/j.ajo.2020.08.037

23. Erdem CZ, Altin R, Erdem LO, Kargi S, Kart L, Cinar F, Ayoglu F (2003) Doppler measurement of blood flow velocities in extraocular orbital vessels in patients with obstructive sleep apnea syndrome. J Clin Ultrasound 31:250-257. https://doi.org/10.1002/ jcu. 10171

24. Mentek M, Morand J, Baldazza M, Faury G, Aptel F, Pepin JL, Godin-Ribuot D, Chiquet C (2018) Chronic Intermittent Hypoxia Alters Rat Ophthalmic Artery Reactivity Through Oxidative Stress, Endothelin and Endothelium-Derived Hyperpolarizing Pathways. Invest Ophthalmol Vis Sci 59:5256-5265. https://doi. org/10.1167/iovs.18-25151

25. Himori N, Ogawa H, Ichinose M, Nakazawa T (2020) CPAP therapy reduces oxidative stress in patients with glaucoma and OSAS and improves the visual field. Graefes Arch Clin Exp Ophthalmol 258:939-941. https://doi.org/10.1007/s00417-019-04483-z

26. Turnbull CD, Heitmar R (2021) Letter to the editor relating to Graefe's Arch Clin Exp Ophthalmol 2020 258:939-941. "CPAP therapy reduces oxidative stress in patients with glaucoma and OSAS and improves the visual field." Graefes Arch Clin Exp Ophthalmol 259:1079-1080. https://doi.org/10.1007/ s00417-020-04823-4

27. Chopra S, Polotsky VY, Jun JC (2016) Sleep apnea research in animals. Past, present, and future. Am J Respir Cell Mol Biol 54:299-305. https://doi.org/10.1165/rcmb.2015-0218TR

28. Chen L, Zhao Y, Zhang H (2016) Comparative anatomy of the trabecular meshwork, the optic nerve head and the inner retina in rodent and primate models used for glaucoma research. Vision (Basel) 1. https://doi.org/10.3390/vision1010004

29. Tong JY, Golzan M, Georgevsky D, Williamson JP, Graham SL, Farah CS, Fraser CL (2017) Quantitative retinal vascular changes in obstructive sleep apnea. Am J Ophthalmol 182:72-80. https:// doi.org/10.1016/j.ajo.2017.07.012

30. Wong B, Tong JY, Schulz AM, Graham SL, Farah CS, Fraser CL (2021) The impact of continuous positive airway pressure treatment on retinal vascular changes in obstructive sleep apnea. J Clin Sleep Med 17:983-991. https://doi.org/10.5664/jcsm.9118

31. Cammaroto G, Costa F, Ruiz MVG, Ando G, Vicini C, Montevecchi F, Galletti C, Galletti F, Valgimigli M (2019) Obstructive sleep apnoea syndrome and endothelial function: potential impact of different treatment strategies-meta-analysis of prospective studies. Eur Arch Otorhinolaryngol 276:2331-2338. https://doi.org/ 10.1007/s00405-019-05486-6

32. Ning Y, Zhang TS, Wen WW, Li K, Yang YX, Qin YW, Zhang HN, Du YH, Li LY, Yang S, Yang YY, Zhu MM, Jiao XL, Zhang Y, Zhang M, Wei YX (2019) Effects of continuous positive airway pressure on cardiovascular biomarkers in patients with obstructive sleep apnea: a meta-analysis of randomized controlled trials. Sleep Breath 23:77-86. https://doi.org/10. 1007/s11325-018-1662-2

33. Thiel S, Lettau F, Rejmer P, Rossi C, Haile SR, Schwarz EI, Stoberl AS, Sievi NA, Boss A, Becker AS, Winklhofer S, Stradling JR, Kohler M (2019) Effects of short-term continuous positive airway pressure withdrawal on cerebral vascular reactivity measured by blood oxygen level-dependent magnetic resonance imaging in obstructive sleep apnoea: a randomised controlled trial. Eur Respir J 53. https://doi.org/10.1183/13993003.01854-2018

34. Schwarz EI, Schlatzer C, Stehli J, Kaufmann PA, Bloch KE, Stradling JR, Kohler M (2016) Effect of CPAP Withdrawal on myocardial perfusion in OSA: a randomized controlled trial. Respirology 21:1126-1133. https://doi.org/10.1111/resp.12798

35. Joannides R, Haefeli WE, Linder L, Richard V, Bakkali EH, Thuillez C, Luscher TF (1995) Nitric oxide is responsible for flowdependent dilatation of human peripheral conduit arteries in vivo. Circulation 91:1314-1319. https://doi.org/10.1161/01.cir.91.5. 1314

36. Mullen MJ, Kharbanda RK, Cross J, Donald AE, Taylor M, Vallance P, Deanfield JE, MacAllister RJ (2001) Heterogenous nature of flow-mediated dilatation in human conduit arteries in vivo: relevance to endothelial dysfunction in hypercholesterolemia. Circ Res 88:145-151. https://doi.org/10.1161/01.res.88.2.145

37. Nohria A, Gerhard-Herman M, Creager MA, Hurley S, Mitra D (1985) Ganz P (2006) Role of nitric oxide in the regulation of digital pulse volume amplitude in humans. J Appl Physiol 101:545-548. https://doi.org/10.1152/japplphysiol.01285.2005

38. Metea MR, Newman EA (2007) Signalling within the neurovascular unit in the mammalian retina. Exp Physiol 92:635-640. https:// doi.org/10.1113/expphysiol.2006.036376

39. Frederiksen CA, Jeppesen P, Knudsen ST, Poulsen PL, Mogensen CE, Bek T (2006) The blood pressure-induced diameter response of retinal arterioles decreases with increasing diabetic maculopathy. Graefes Arch Clin Exp Ophthalmol 244:1255-1261. https:// doi.org/10.1007/s00417-006-0262-1

40. Jeppesen P, Gregersen PA, Bek T (2004) The age-dependent decrease in the myogenic response of retinal arterioles as studied with the Retinal Vessel Analyzer. Graefes Arch Clin Exp Ophthalmol 242:914-919. https://doi.org/10.1007/s00417-004-0945-4

41. Zhu Z, Zhang F, Liu Y, Yang S, Li C, Niu Q, Niu J (2017) Relationship of obstructive sleep apnoea with diabetic retinopathy: a meta-analysis. Biomed Res Int 2017:4737064. https://doi.org/10. 1155/2017/4737064

42. Mandecka A, Dawczynski J, Blum M, Muller N, Kloos C, Wolf G, Vilser W, Hoyer H, Muller UA (2007) Influence of flickering light on the retinal vessels in diabetic patients. Diabetes Care 30:3048-3052. https://doi.org/10.2337/dc07-0927 
43. Nguyen TT, Kawasaki R, Wang JJ, Kreis AJ, Shaw J, Vilser W, Wong TY (2009) Flicker light-induced retinal vasodilation in diabetes and diabetic retinopathy. Diabetes Care 32:2075-2080. https://doi.org/10.2337/dc09-0075

44. West SD, Prudon B, Hughes J, Gupta R, Mohammed SB, Gerry S, Stradling JR, investigators Rt (2018) Continuous positive airway pressure effect on visual acuity in patients with type 2 diabetes and obstructive sleep apnoea: a multicentre randomised controlled trial. Eur Respir J 52. https://doi.org/10.1183/13993003. 01177-2018

45. Heitmar R, Vonthein R (2021) Clinically valid conclusions from retinal photographs need the best formulae. Graefes Arch Clin Exp Ophthalmol 259:811-813. https://doi.org/10.1007/ s00417-020-05062-3
46. Pack AI, Magalang UJ, Singh B, Kuna ST, Keenan BT, Maislin G (2021) Randomized clinical trials of cardiovascular disease in obstructive sleep apnea: understanding and overcoming bias. Sleep 44. https://doi.org/10.1093/sleep/zsaa229

47. McEvoy RD, Sanchez-de-la-Torre M, Peker Y, Anderson CS, Redline S, Barbe F (2021) Randomized clinical trials of cardiovascular disease in obstructive sleep apnea: understanding and overcoming bias. Sleep 44. https://doi.org/10.1093/sleep/zsab019

Publisher's note Springer Nature remains neutral with regard to jurisdictional claims in published maps and institutional affiliations.

\section{Authors and Affiliations}

\section{Chris D. Turnbull, ${ }^{1}$ (D) James A. Stockley ${ }^{3} \cdot$ Shyam Madathil $^{3} \cdot$ Syed S. A. Huq ${ }^{3} \cdot$ Brendan G. Cooper $^{3} \cdot$ Asad Ali $^{4}$. Simon Wharton ${ }^{5} \cdot$ John R. Stradling ${ }^{2} \cdot$ Rebekka Heitmar $^{6}$}

1 Nuffield Department of Medicine, University of Oxford, Oxford, UK

2 NIHR Biomedical Research Centre, University of Oxford, Oxford, UK

3 Lung Function \& Sleep, Queen Elizabeth Hospital, University Hospitals Birmingham NHSFT,

Birmingham B15 2GW, West Midlands, UK

4 Department of Sleep and Respiratory Medicine, University Hospital Coventry and Warwickshire, Coventry CV2 2DX, Warwickshire, UK
5 Sleep Department, Heartlands Hospital, University Hospitals Birmingham NHSFT, Birmingham B15 2GW, West Midlands, UK

6 School of Applied Sciences, Department of Optometry and Vision Sciences, University of Huddersfield, Huddersfield, UK 